\title{
The Vascular Site of Action of Hypoxia in the Neonatal Pig Lung
}

\author{
LEIF D. NELIN, DAVID A. RICKABY, JOHN H. LINEHAN, AND CHRISTOPHER A. DAWSON \\ Departments of Pediatrics [L.D.N.] and Physiology [D.A.R., C.A.D.]. Medical College of Wisconsin. Milwaukee, \\ Wisconsin 53226; Research Service [L.D.N., D.A.R., J.H.L., C.A.D.J. Zablocki Veteran's Administration Medical \\ Center, Milwaukee, Wisconsin 53295; and Biomedical Engineering Department [J.H.L.J, Marquette University,
} Milwaukee, Wisconsin 53233

\begin{abstract}
To determine the vascular site(s) of action of hypoxia in the neonatal pig, isolated lungs were perfused at a constant flow rate and left atrial pressure; arterial, venous, and double occlusions were performed. The distribution of the total pulmonary vascular resistance and the total dynamic vascular compliance were calculated using a model of the pulmonary circulation consisting of upstream, central, and downstream compliances and resistances upstream and downstream of central compliance. In addition, the static vascular compliance was measured by venous followed by arterial occlusion, and the total vascular volume was measured by dye-dilution. In this preparation during control conditions alveolar $\mathrm{PO}_{2}=12 \pm 2 \mathrm{kPa}$ ), total pulmonary vascular resistance was nearly evenly divided between resistance upstream and downstream of double occlusion pressure and total dynamic vascular compliance was concentrated mainly in the central compliance $(7 \%$ upstream compliance, $82 \%$ central compliance, and $11 \%$ downstream compliance). Hypoxia (alveolar $\mathrm{Po}_{2}=4 \pm 1$ $\mathrm{kPa}$ ) increased both resistance upstream of double occlusion pressure $(p<0.005)$ and resistance downstream of double occlusion pressure $(p<0.02)$ and decreased central compliance $(p<0.005)$. Hypoxia also decreased total pulmonary blood volume $(p<0.02)$. These results suggest that in the pulmonary vasculature of the neonatal pig, hypoxia results mainly in 1) arterial constriction as evidenced by a large increase in upstream resistance and a decrease in total pulmonary blood volume and 2) a smaller but significant venous constriction. This venous constriction may have implications in the pathogenesis and therapy of pulmonary vascular diseases associated with hypoxia such as postasphyxial lung disease and bronchopulmonary dysplasia. (Pediatr Res 35: 25-29, 1994)
\end{abstract}

\section{Abbreviations}

$P_{\text {n, pulmonary arterial pressure }}$

$P_{v}$, left atrial pressure

$P_{\mathrm{d}}$, double occlusion pressure

$\mathbf{R}_{\mathrm{L}}$, total pulmonary vascular resistance

$\mathbf{R}_{\mathbf{u}}$, resistance upstream of $\mathbf{P}_{\mathrm{d}}$

$R_{d}$, resistance downstream of $P_{d}$

$C_{t t}$, total pulmonary vascular static compliance

$C_{d y n}$, total pulmonary vascular dynamic compliance

$\mathrm{C}_{u}$, upstream compliance

$C_{c}$, central compliance

$C_{d}$, downstream compliance

$Q_{L}$, total pulmonary blood volume

Received June 23, 1993; accepted August 27, 1993.

Correspondence: Leif D. Nelin, M.D., Research Service 151, Zablocki VA Medical Center, 5000 W. National Avenue, Milwaukee, WI 53295.

Supported in part by Grant HL-19298 and the Department of Veterans Affairs.
VOAO, venous followed by arterial occlusion

VO, venous occlusion

DO, double occlusion

AO, arterial occlusion

$\underline{S}$, pressure relaxation

$\overline{\mathbf{t}}_{\mathrm{R}}$, mean relaxation time

The neonate is at a high risk for pulmonary vascular diseases that manifest increased pulmonary vascular resistance such as persistent pulmonary hypertension of the newborn, bronchopulmonary dysplasia, and certain forms of congenital heart disease (1). The neonatal pig has been used extensively as a model for pulmonary vascular development and disease $(2-14)$ because the postnatal morphometric pulmonary development closely parallels the human but on a more compact time scale (14). Typically, pulmonary arterial pressure and flow have been measured during conditions that mimic certain aspects of pulmonary vascular disease (3-14), such as alveolar hypoxia. The pressure and flow data alone provide an incomplete picture of the pulmonary vascular response. For example, the arterial and/or venous site of action may be important in determining the impact on cardiopulmonary function. In the adult, it has been shown that hypoxia causes arterial constriction (15-21), which implies a risk for right ventricular failure, but not necessarily for pulmonary edema because capillary pressure would not be affected. On the other hand, in the neonatal pig (2) and lamb (22) there is some evidence that the pulmonary veins may be involved in the hypoxic response. This would have implications for lung fluid balance, and thus, in the pathogenesis and treatment of vascular diseases in which hypoxia is a major component, such as postasphyxial lung disease of the neonate.

Certain aspects of pulmonary vascular function are more easily studied in isolated lungs than in the intact animal. Therefore, the present study was carried out to determine the influence of hypoxia on this preparation in terms of site of action and impact on viscoelasticity of the vascular bed.

\section{MATERIALS AND METHODS}

The lungs from eight neonatal pigs $[2.8 \pm 0.7$ (SD) $\mathrm{kg}, 8.9 \pm$ $5.3 \mathrm{~d}$ old] were used in an isolated perfused preparation as previously described (23). Each pig was anesthetized with a mixture of ketamine hydrochloride $(30 \mathrm{mg} / \mathrm{kg})$ and acepromazine maleate, $(1.5 \mathrm{mg} / \mathrm{kg})$ given intramuscularly. A carotid artery catheter was inserted and an arterial sample was obtained for blood gas analysis and hematocrit with the following result: $\mathrm{PO}_{2}$ $12.0 \pm 2.0 \mathrm{kPa}(90 \pm 15 \mathrm{~mm} \mathrm{Hg}), \mathrm{PCO}_{2} 5.6 \pm 0.5 \mathrm{kPa}(42 \pm 4$ $\mathrm{mm} \mathrm{Hg}), \mathrm{pH} 7.22 \pm 0.07$, and hematocrit $0.22 \pm 0.05(22 \pm$ $5 \%$ ). Then 1250 units $/ \mathrm{kg}$ of heparin and 15 to $20 \mathrm{~mL} / \mathrm{kg}$ of $10 \%$ 
dextran were given intra-arterially and the piglet was exsanguinated. The autologous blood (resultant hematocrit $0.13 \pm 0.03$ or $13 \pm 3 \%$ ) was used to prime the perfusion system. The perfusion system consisted of a reservoir, a Masterflex roller pump with a 7016 head, a heat exchanger, and an injector. The trachea was clamped and a median sternotomy was performed. Rigid cannulas were placed in the main pulmonary artery and the left atrium. The lungs and heart were removed en bloc and suspended in a heated humidified perfusion chamber. The blood was recirculated through the lungs at a flow rate of $95 \pm 10 \mathrm{~mL} \cdot \mathrm{min}^{-1}$. $\mathrm{kg}^{-1}$. The venous effluent drained into a reservoir, the height of which could be adjusted to set the venous pressure at the desired level. The $P_{a}, P_{v}$, and airway pressures were continuously recorded. Vascular pressures were referenced to the height of the left atrium. Ventilation was begun with a gas mixture containing $\sim 6 \% \mathrm{CO}_{2}, 15 \% \mathrm{O}_{2}$ in $\mathrm{N}_{2}$ using a Harvard piston-type respirator with a tidal volume of $91 \pm 19 \mathrm{~mL}$ and a frequency of 22 breaths/min.

When the arterial pressure was stable, the respirator was turned off at end expiration. The following vascular occlusion maneuvers were carried out in zone III conditions as described previously $(15,24,25)$, VOAO and then a second VOAO, DO, and AO. The first VOAO was carried out as a conditioning maneuver (26). The second VOAO and the DO, and AO pressure curves, digitized at $40 \mathrm{~Hz}$, were analyzed as described below. The time interval between the venous and arterial occlusion for the VOAO maneuver was approximately $3 \mathrm{~s}(3.3 \pm 0.6 \mathrm{~s}$ during the control condition and $3.1 \pm 0.4 \mathrm{~s}$ during hypoxia).

In seven of the lungs, indicator dilution measurements of $\mathrm{Q}_{\mathrm{L}}$ were also made before and after the occlusion maneuvers. A bolus of indocyanine green ( $50 \mu \mathrm{g}$ in $0.4 \mathrm{~mL}$ of water) was introduced into the arterial inflow via the injector. A portion of the venous effluent was continuously passed through a Gilson densitometer. The output from the densitometer was digitized at $40 \mathrm{~Hz}$ for later analysis.

After the measurements described above were completed, the ventilating gas mixture was changed to $4 \% \mathrm{O}_{2}$, and $6 \% \mathrm{CO}_{2}$ in $\mathrm{N}_{2}$ and the respirator was turned on. When arterial pressure had stabilized, the respirator was turned off at end expiration and the vascular occlusions and dye dilution measurements were repeated as described above.

Calculations. The pressure versus time curves obtained from a typical VOAO experiment are shown in Figure $1 A$. After the relatively sudden jump in $P_{v}$ after occlusion from the preocclusion value, $P_{v}(0)$, the venous pressure curve, $P_{v}(t)$, increases in an almost linear fashion. For a short time after VO, the arterial pressure is nearly constant at its preocclusion value, $\mathrm{P}_{\mathrm{a}}(0)$. Subsequently, the arterial pressure curve, $P_{a}(t)$, is also observed to increase with time nearly in parallel with $P_{v}(t)$. These slow increases in vascular pressure after $\mathrm{VO}$ are caused by the linear increase in lung vascular volume, $\mathrm{Q}_{\mathrm{L}}$, resulting from the constant inflow, $Q$. The rate at which vascular pressure increases after VO is inversely proportional to the vascular compliance (24). That is

$$
\mathrm{C}_{\mathrm{dyn}}=\frac{\mathrm{dQ}_{\mathrm{L}}}{\mathrm{dP}}=\frac{\mathrm{dQ} \mathrm{L} / \mathrm{dt}}{\mathrm{dP} / \mathrm{dt}}=\frac{\dot{\mathrm{Q}}}{\dot{\mathrm{P}}}
$$

where $C_{d y n}$ is the dynamic vascular compliance obtained from the venous occlusion data and $\dot{P}$ is the slope of the pressure versus time curve over the interval from 0.2 to $1.0 \mathrm{~s}$ after VO. For the data such as in Figure $1 A$, the slopes of $\mathrm{P}_{\mathrm{a}}(\mathrm{t})$ and $\mathrm{P}_{\mathrm{v}}(\mathrm{t})$ during this time interval are not exactly equal. Therefore, we use the mean slope defined as

$$
\dot{\mathrm{P}}_{\mathrm{m}}=\frac{\dot{\mathrm{P}}_{\mathrm{a}}+\dot{\mathrm{P}}_{\mathrm{v}}}{2}
$$

in equation 1.

The dynamic vascular compliance obtained from the VO data is, in general, smaller than vascular compliance calculated from

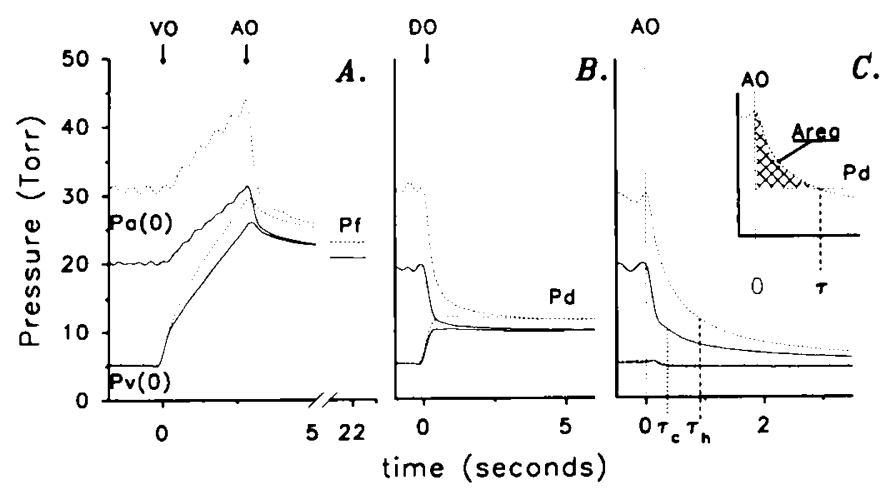

Fig. 1. $A$, Typical VOAO in an isolated perfused neonatal pig lung during control (solid lines) and hypoxic (dashed lines) conditions. The instant of $\mathrm{VO}$ is designated by the arrow at time 0 ; the instant of $A O$ is designated by the arrow at about $3.0 \mathrm{~s}$. The $\Delta \mathrm{Q}_{\mathrm{L}}$ that occurred between $\mathrm{VO}$ and $\mathrm{AO}$ is equal to the time between $\mathrm{VO}$ and $\mathrm{AO}(\Delta \mathrm{t})$ multiplied by the flow rate $(Q) . P_{a}(0)$ and $P_{v}(0)$ represent the arterial and venous pressures before occlusion and $P_{f}$ is the final equilibrium pressure after VOAO. B, Typical DO in an isolated perfused neonatal pig lung during control (solid line) and hypoxic (dashed line) conditions. The instant of occlusion is designated time 0 and $P_{d}$ indicates the DO pressure. In this case $\Delta \mathrm{t}=0$ and therefore $\Delta \mathrm{Q}_{\mathrm{L}}=0 . C$, Typical $\mathrm{AO}$ in an isolated perfused neonatal pig lung during control (solid line) and hypoxic (dashed line) conditions. The instant of occlusion is designated time 0 , and $\tau_{\mathrm{c}}$ and $\tau_{\mathrm{h}}$ represent the time when $P_{d}(t)$ reaches $P_{d}$ for control and hypoxic conditions, respectively. The term area used in equation 7 is defined as the integral from 0 to $\tau$ of $(\mathrm{dPa}(\mathrm{t})-\mathrm{Pd})$ and is shown graphically in the inset for the hypoxic $\mathrm{Pa}(\mathrm{t})$ curve.

static (equilibrium) conditions (24). A measure of the $C_{s t}$ can also be obtained from the occlusion experiments. During the VO portion of the VOAO maneuver, the lobar vascular volume increases linearly with time. If after a given time, the arterial outflow is also occluded, AO, a known volume increment of blood, $\Delta \mathrm{Q}_{\mathrm{L}}$, is trapped within the lungs, i.e. $\Delta \mathrm{Q}_{\mathrm{L}}=\mathrm{Q} \Delta \mathrm{t}$, where $\Delta t$ is the time interval between $\mathrm{VO}$ and $\mathrm{AO}$ (Fig. $1 A$ ). Under the isovolumic conditions following $\mathrm{AO}$, both $\mathrm{P}_{\mathrm{a}}$ and $\mathrm{P}_{\mathrm{v}}$ decreased to a common asymptotic equilibrium pressure $\left(P_{f}\right)$. When the pulmonary artery and vein are simultaneously occluded, both $\Delta t$ $=0$ and $\Delta \mathrm{Q}_{\mathrm{L}}=0$ and the resulting final equilibrium pressure is denoted the double occlusion pressure, $P_{d}$ (Fig. $1 B$ ) and represents the microvascular pressure $(15,24)$. The average value of $\mathrm{C}_{\mathrm{st}}$ over the pressure range studied during the VOAO maneuver can then be calculated as

$$
\mathrm{C}_{\mathrm{st}}=\frac{\Delta \mathrm{Q}_{\mathrm{L}}}{\mathrm{P}_{\mathrm{f}}-\mathrm{P}_{\mathrm{d}}}
$$

The VOAO data provided additional information related to the viscoelasticity of the pulmonary vascular bed. The pressure curves after $\mathrm{AO}$ exhibit stress relaxation, i.e. $\mathrm{P}_{\mathrm{f}}$ is less than either $\mathrm{P}_{\mathrm{a}}$ or $\mathrm{P}_{\mathrm{v}}$ were at the time of $\mathrm{AO}$ (Fig. $1 A$ ). The magnitude of $\mathrm{S}$, in millimeters of mercury per milliliter change in blood volume, that the vessels undergo after $\mathrm{AO}$ is

$$
S=\frac{1}{C_{d y n}}-\frac{1}{C_{s t}}
$$

The mean relaxation time in seconds characterizing the time course of the relaxation pressure after AO can be estimated by fitting the pressure curve after $\mathrm{AO}$ to

$$
P_{v}(t)-P_{f}=A_{1} e^{-\beta_{1} t}+A_{2} e^{-\beta_{2} t}
$$

by nonlinear regression (24). The $\bar{t}_{R}$ is then defined as

$$
\bar{t}_{R}=\frac{\frac{A_{1}}{\beta_{1}}+\frac{A_{2}}{\beta_{2}}}{A_{1}+A_{2}}
$$


The occlusion data were also used to characterize the compartmental distribution of the dynamic vascular compliance and vascular resistance as defined previously (27). In the compartmental model used to interpret the data, the large arteries and veins are represented by $C_{u}$ and $C_{d}$, respectively. The small vessels are represented by $R_{u}$ and $R_{d}$, respectively, which are located upstream and downstream from $\mathrm{C}_{\mathrm{c}}$ representing the compliance of the microvasculature including the capillaries. Changes in $R_{u}$ and $R_{d}$, are considered to represent mainly changes in the vascular resistance of the small arteries and veins, respectively (27). The data obtained from the $\mathrm{VO}, \mathrm{DO}$, and $\mathrm{AO}$ maneuvers (examples are shown for control and hypoxia in Fig. 1) were used to estimate $R_{u}, R_{d}, C_{u}, C_{d}$, and $C_{c}$ using the following equations (25).

$$
\begin{gathered}
\frac{P_{a}(0)-P_{v}(0)}{Q}=R_{u}+R_{d}=R_{L} \\
R_{u}=\frac{\left(P_{a}(0)-P_{d}\right)}{\dot{Q}} \\
R_{d}=R_{L}-R_{u} \\
C_{u}=\frac{A r e a}{\left(P_{a}(0)-P_{d}\right) R_{u}} \\
C_{c}=C_{d y n}-R_{L} C_{u} \cdot \frac{1}{R_{d}} \\
C_{d}=C_{d y n}-C_{u}-C_{c}
\end{gathered}
$$

In addition to the occlusion data, pulmonary blood volume was measured using a bolus injection of indocyanine green as previously described (23). The first moment and the second moment about the mean of the indicator dilution curves, which represent the mean transit time, and the variance of the transit times for the passage of the dye bolus through the lungs, respectively, were calculated (23). The $\mathrm{Q}_{\mathrm{L}}$ accessible to the dye was then the mean transit time times the flow rate. The relative dispersion of the dye bolus as it passed through the lungs was calculated as the square root of the variance divided by the transit time.

Comparisons between control and hypoxic conditions were made using the $t$ test for paired samples. Differences are considered significant at $p<0.05$.

\section{RESULTS}

The ventilator settings used for these studies resulted in a peak inspiratory pressure (PIP) of $1.2 \pm 0.3 \mathrm{kPa}(8.8 \pm 2.0 \mathrm{~mm} \mathrm{Hg})$, an end-expiratory pressure (EEP) of $0.2 \pm 0.1 \mathrm{kPa}(1.8 \pm 1.0$ $\mathrm{mm} \mathrm{Hg}$ ) and a lung compliance, defined as $V_{T} /(P I P-E E P)$, of $101 \pm 25 \mathrm{~mL} \cdot \mathrm{kPa}^{-1}\left(13.5 \pm 3.3 \mathrm{~mL} \mathrm{~mm} \mathrm{Hg} \mathrm{Hg}^{-1}\right)$ and the lung compliance was stable over the course of an experiment. The blood gas tensions during normoxic ventilation were $\mathrm{a} \mathrm{PO}_{2}$ of $12.4 \pm 1.6 \mathrm{kPa}(93 \pm 12 \mathrm{~mm} \mathrm{Hg})$ and a $\mathrm{PCO}_{2}$ of $5.5 \pm 0.7 \mathrm{kPa}$ $(41 \pm 5 \mathrm{~mm} \mathrm{Hg})$ with a pH of $7.43 \pm 0.14$. The blood gas tensions during hypoxic ventilation were a $\mathrm{Po}_{2}$ of $4.0 \pm 0.8 \mathrm{kPa}$ $(30 \pm 6 \mathrm{~mm} \mathrm{Hg})$ and $\mathrm{a} \mathrm{PCO}_{2}$ of $5.6 \pm 0.7 \mathrm{kPa}(42 \pm 5 \mathrm{~mm} \mathrm{Hg})$ with a $\mathrm{pH}$ of $7.48 \pm 0.06$.

The hemodynamic data are summarized in Table 1 . The total pulmonary vascular resistance was nearly evenly divided upstream and downstream of the microvascular pressure, $P_{d}$, during control conditions. Hypoxia increased both the $R_{u}$ and $R_{d}$ but, the increase in $\mathbf{R}_{\mathbf{u}}$ was greater $(p<0.02)$ than the increase in $\mathbf{R}_{\mathbf{d}}$ (Table 1). Hypoxia also resulted in a significant decrease in $C_{d y n}$ which could be accounted for by the decrease in $\mathrm{C}_{\mathrm{c}}$ (Table 1). However, there was no significant change detected in $C_{s t}$ with hypoxia (Table 1). This difference between $\mathrm{C}_{\text {dyn }}$ and $\mathrm{C}_{\mathrm{st}}$, suggests an increase in the viscous resistance to distension in vessels that responded to hypoxia. This increase in viscous resistance is also revealed by the increase in the magnitude of $S$ and the decrease
Table 1. Hemodynamic data*

\begin{tabular}{lcc}
\hline & Control & Hypoxia \\
\hline $\mathrm{P}_{\mathrm{L}}(0)(\mathrm{mm} \mathrm{Hg})$ & $17.7 \pm 1.1$ & $27.7 \pm 2.2 \ddagger$ \\
$\mathrm{P}_{\mathrm{v}}(0)(\mathrm{mm} \mathrm{Hg})$ & $4.1 \pm 0.3$ & $4.1 \pm 0.3$ \\
$\mathrm{P}_{\mathrm{d}}(\mathrm{mm} \mathrm{Hg})$ & $9.8 \pm 0.9$ & $12.2 \pm 1.3 \dagger$ \\
$\mathrm{P}_{\mathrm{f}}(\mathrm{mm} \mathrm{Hg})$ & $26.3 \pm 1.7$ & $24.9 \pm 2.1$ \\
$\mathrm{R}_{\mathrm{L}}\left(\mathrm{mm} \mathrm{Hg} \cdot \mathrm{mL}^{-1} \cdot \mathrm{s}\right)$ & $3.29 \pm 0.42$ & $5.66 \pm 0.70 \ddagger$ \\
$\mathrm{R}_{\mathrm{u}}\left(\mathrm{mm} \mathrm{Hg} \cdot \mathrm{mL}^{-1} \cdot \mathrm{s}\right)$ & $1.98 \pm 0.31$ & $3.70 \pm 0.57 \ddagger$ \\
$\mathrm{R}_{\mathrm{d}}\left(\mathrm{mm} \mathrm{Hg} \cdot \mathrm{mL}^{-1} \cdot \mathrm{s}\right)$ & $1.47 \pm 0.29$ & $2.09 \pm 0.43 \dagger$ \\
$\mathrm{C}_{\mathrm{dyn}}\left(\mathrm{mL} \cdot \mathrm{mm} \mathrm{Hg}^{-1}\right)$ & $0.67 \pm 0.07$ & $0.50 \pm 0.04 \ddagger$ \\
$\mathrm{C}_{\mathrm{u}}\left(\mathrm{mL} \cdot \mathrm{mm} \mathrm{Hg}^{-1}\right)$ & $0.05 \pm 0.01$ & $0.06 \pm 0.01$ \\
$\mathrm{C}_{\mathrm{c}}\left(\mathrm{mL} \cdot \mathrm{mm} \mathrm{Hg}^{-1}\right)$ & $0.53 \pm 0.05$ & $0.33 \pm 0.02 \ddagger$ \\
$\mathrm{C}_{\mathrm{d}}\left(\mathrm{mL} \cdot \mathrm{mm} \mathrm{Hg}^{-1}\right)$ & $0.07 \pm 0.02$ & $0.13 \pm 0.03 \dagger$ \\
$\Delta \mathrm{Q}_{\mathrm{L}}(\mathrm{mL})$ & $14.3 \pm 1.8$ & $13.3 \pm 1.4$ \\
$\mathrm{C}_{\mathrm{st}}\left(\mathrm{mL} \cdot \mathrm{mm} \mathrm{Hg}^{-1}\right)$ & $0.87 \pm 0.10$ & $0.99 \pm 0.08$ \\
$\mathrm{~S}\left(\mathrm{~mm} \mathrm{Hg} \cdot \mathrm{mL}^{-1}\right)$ & $0.38 \pm 0.10$ & $1.00 \pm 0.13 \ddagger$ \\
$\mathrm{t}_{\mathrm{R}}(\mathrm{s})$ & $5.67 \pm 0.82$ & $3.43 \pm 0.43 \dagger$ \\
$\mathrm{Q}_{\mathrm{L}}(\mathrm{mL})$ & $21.2 \pm 1.9$ & $17.1 \pm 1.8 \dagger$ \\
$\mathrm{Relative} \mathrm{dispersion}$ & $0.48 \pm 0.04$ & $0.53 \pm 0.06$ \\
\hline
\end{tabular}

* Values are $\pm \mathrm{SE}$.

+ Different from control, $p<0.02$.

$\ddagger$ Different from control, $p<0.005$.

in $\bar{t}_{R}$. Hypoxia also resulted in a consistent decrease in $Q_{L}$. with no significant change in relative dispersion (Table 1).

\section{DISCUSSION}

According to the resistor-capacitator model interpretation of the occlusion data, the distribution of vascular resistance in the neonatal pig lung under normoxic zone III conditions was nearly evenly divided upstream and downstream of $P_{d}$ and $C_{c}$. It is generally felt that $P_{d}$ is close to the average capillary pressure (15, $21,24,25,28,37)$. Thus, this observation is consistent with the results of Fike and Kaplowitz (2) who found that vascular resistance was nearly evenly divided upstream and downstream of $10-$ to $60-\mu \mathrm{m}$ diameter subpleural venules in the isolated lungs from 6- to 7-d-old pigs, assuming that the resistance between 10$\mu \mathrm{m}$ arteries and veins is small. A nearly equal distribution of vascular resistance upstream and downstream of $P_{d}$ using vascular occlusions has also been reported in the isolated lungs from 12- to 13-week-old Minipigs and 12-week-old Landrace pigs (29). The distribution of vascular compliance between arterial, microvascular and venous segments under normoxic conditions was about 7,82 , and $11 \%$, respectively. This distribution is consistent with previous studies in isolated adult dog lungs using this and other methods (15, 24, 27, 30, 31).

The results indicate that the increase in total vascular resistance due to hypoxia occurred mainly in the pulmonary arteries in this preparation. This conclusion is based on two observations. First, the vascular occlusion data interpreted according to the compartmental model indicate that much of the increase was in $R_{u}$. Second, the decrease in $Q_{L}$ is consistent with a predominantly arterial site of action $(16,32)$, because a predominantly venous site of action would be expected to increase rather than decrease $Q_{L}(16,32)$. An arterial site of action of hypoxia has been a consistent finding in the adult lungs from many different species $(15-21,24,25,32)$. However, we found that in these neonatal pig lungs there was a significant downstream response as well. This is consistent with the findings of Fike and Kaplowitz (2) in the isolated lungs from 6- to 7-d-old pig lungs. A maturational difference in the hypoxic response has been suggested in some species. For example, in the pig (5) and in the rabbit (33) it has been found that the magnitude of the hypoxic pressure response, expressed as the percent change in pulmonary artery pressure, increases with increasing postnatal age. Also, lung lymph fistula studies in sheep $(19,22)$ have suggested that hypoxia resulted in an increase in microvascular pressure in the lamb but not in the sheep. However, in the juvenile pig (2-3 mo of age) Mitzner and 
Table 2. Pulmonary hemodynamics in intact neonatal pigs*

\begin{tabular}{lcccccc}
\hline First author & Reference & $\begin{array}{c}\text { Age } \\
(\mathrm{d})\end{array}$ & $\begin{array}{c}\text { Weight } \\
(\mathrm{kg})\end{array}$ & $\begin{array}{c}\mathrm{PBF} \\
\left(\mathrm{mL} \cdot \mathrm{min}^{-1} \cdot \mathrm{kg}^{-1}\right)\end{array}$ & $\begin{array}{c}\mathrm{P}_{\mathrm{g}}-\mathrm{P}_{\mathrm{w}} \\
(\mathrm{mm} \mathrm{Hg})\end{array}$ & $\begin{array}{c}\mathrm{R}_{\mathrm{L}} \\
\left(\mathrm{mm} \mathrm{Hg} \cdot \mathrm{mL}^{-1} \cdot \mathrm{s}\right)\end{array}$ \\
\hline Redding & 3 & $5-12$ & $2.6 \pm 0.7$ & $200 \pm 85$ & $11 \pm 4$ & $2.7 \pm 1.2$ \\
Bradley & 4 & $<10$ & $2.5-4.2$ & $142 \pm 57$ & $7 \pm 3$ & $0.8 \pm 0.1$ \\
Our study & & $9 \pm 5$ & $2.8 \pm 0.7$ & $95 \pm 10$ & $14 \pm 3$ & $3.3 \pm 0.4$ \\
Konduri & 5 & 10 & $3.4 \pm 0.3$ & $241 \pm 48$ & $19 \pm 9$ & $1.4 \pm 0.5$ \\
Taylor & 6 & $10-12$ & $2.9 \pm 0.6$ & $285 \pm 43$ & $15 \pm 3$ & $1.1 \pm 0.2$ \\
Goldberg & 7 & $11 \pm 4$ & $3.3 \pm 0.8$ & $260 \pm 20$ & $10 \pm 4$ & $1.0 \pm 0.2$ \\
Troug & 8 & $10-16$ & $3.2 \pm 0.6$ & $215 \pm 20$ & $10 \pm 3$ & $0.9 \pm 0.5$ \\
Gibson & 9 & $13 \pm 3$ & $3.6 \pm 0.5$ & $264 \pm 42$ & $11 \pm 1$ & $0.7 \pm 0.1$ \\
Gibson & 10 & $12-18$ & $3.3 \pm 0.7$ & $230 \pm 67$ & $11 \pm 2$ & $0.8 \pm 0.1$ \\
Troug & 11 & $17 \pm 7$ & $4.1 \pm 0.8$ & $260 \pm 100$ & $10 \pm 3$ & $0.5 \pm 0.2$ \\
Gibson & 12 & $18 \pm 4$ & $3.5 \pm 1.5$ & $271 \pm 85$ & $11 \pm 5$ & $0.7 \pm 0.1$ \\
Rendas & 13 & $14-28$ & 6.7 & $85 \pm 19$ & $10 \pm 3$ & $1.1 \pm 0.4$ \\
Rendas & 14 & $14-28$ & $7.3 \pm 3.0$ & $125 \pm 24$ & $16 \pm 4$ & $1.1 \pm 0.4$ \\
\hline
\end{tabular}

* Values are either mean \pm SD or range, order is approximate with respect to average postnatal age. Abbreviations are: PBF, pulmonary blood flow; $P_{a}-P_{w}$, pulmonary arterial minus wedge (or left atrial) pressure.

Sylvester (34) found that hypoxia increased the rate of weight gain in the isolated lung, suggesting that hypoxia led to an increase in the microvascular pressure due to venous constriction. Thus, the age dependence of the venous response apparent in the sheep may not occur in pigs.

The hypoxic pressor response led to a decrease in the dynamic vascular compliance with no significant change in the static vascular compliance, suggesting that hypoxia resulted in an increase in viscous resistance to distension in those vessels which contribute to the vascular compliance. This observation is similar to that in dog lungs using a similar approach (24). Studies in isolated vessels $(26,35)$, have suggested that smooth muscle contributes substantially to the viscous behavior of the vessel wall, and that activation of vascular smooth muscle increases the viscous resistance to distension of the vessel wall $(26,35)$ which is consistent with the increase in $S$ and the decrease in $\bar{t}_{R}$ resulting from hypoxia in this study.

The decrease in the dynamic vascular compliance was almost entirely accounted for by the decrease in $C_{c}$. This has implications regarding the site of action of hypoxia. Although $\mathrm{C}_{c}$ is thought to consist mainly of the capillary bed, it probably includes reactive small arteries and veins as well $(15,24,25,27,28)$. The constriction of these small vessels would be expected to decrease their dynamic compliance and may account for the decrease in $\mathrm{C}_{\mathrm{c}}$. Another possibility that has been proposed is that there is active constriction of capillaries (36). The present methods do not differentiate between these possibilities. An increase in heterogeneity in the resistance and compliance of parallel pathways could also contribute to an apparent difference between $C_{s t}$ and $C_{d y n}(24)$. An increase in the heterogeneity in the resistance and thus in the flow among parallel pathways would be expected to increase the relative dispersion of the dye bolus as it passed through the lungs. However, the observation that the relative dispersion of the dye bolus was not remarkably altered by hypoxia suggests little contribution to the decrease in the calculated $\mathrm{C}_{c}$ from this source (24).

Isolated perfused lungs have several obvious advantages for experimental studies on pulmonary vascular function and metabolism as reflected by their prevalent use in a wide diversity of mechanistic studies. For hemodynamic studies, the question arises whether the isolated perfused lungs are hemodynamically similar to the lungs of intact animals. One disadvantage of the isolated lung is a limited lifetime for experimentation due to either extravascular fluid accumulation or loss of reactivity. One commonly used strategy to extend the useful time of the preparation is to use relatively low flow rates; previous studies using the neonatal pig isolated lung have used flow rates between 10 and $50 \mathrm{~mL} \cdot \mathrm{min}^{-1} \cdot \mathrm{kg}^{-1}(2,37,38)$. To put this into perspective the pressure and flow from the present study and those from published studies in intact neonatal pigs in which both $\mathrm{P}_{\mathrm{a}}$ and wedge pressure were measured are compared in Table 2 . The available data on intact piglets reveals a fairly wide range of pressures and flows. The pressure and flow in this isolated lung preparation under the control conditions were within the ranges of these variables in the intact animal studies, but on the high and low ends of the ranges, respectively. With respect to vessel reactivity, the magnitude of the hypoxic response was comparable to that reported for intact pigs. The mean increase in pulmonary artery pressure was $56 \%$ in our isolated lungs when the breathing gas mixture reduced the $\mathrm{Po}_{2}$ to $4 \pm 0.3 \mathrm{kPa}$. Rendas et al. (13) observed a $44 \%$ increase in pulmonary artery pressure in intact neonatal (2-4 wk of age) pigs when the breathing gas mixture reduced the arterial $\mathrm{Po}_{2}$ to $5.5 \pm 1.1 \mathrm{kPa}$.

In conclusion, we found that in this preparation, the pulmonary vascular resistance was essentially evenly divided upstream and downstream of the central compliance and that most of the vascular compliance was in the microvasculature. Hypoxia resulted mainly in upstream constriction according to the compartmental model used to interpret the data. This conclusion is also consistent with the observed decrease in total vascular volume with hypoxia. However, there was a small but significant downstream constriction. This downstream hypoxic constriction may have implications in lung fluid balance. For example, if human neonates responded in a similar fashion to hypoxia, the increase in microvascular pressure due to downstream constriction may have implications in the pathogenesis and therapy of postasphyxial lung disease and bronchopulmonary dysplasia in the neonate.

Acknowledgment. The authors thank Carol J. Thomas for excellent technical assistance.

\section{REFERENCES}

1. Rabinovitch M 1990 Vascular pathology of PPHNS. In Long WA (ed) Fetal and Neonatal Cardiology. WB Saunders, Philadelphia, pp 656-666

2. Fike CD, Kaplowitz MR 1992 Pulmonary venous pressure increases during alveolar hypoxia in isolated lungs of newborn pigs. J Appl Physiol 73:552556

3. Redding GJ, McMurtry I, Reeves JT 1984 Effects of meclofenamate on pulmonary vascular resistance correlate with postnatal age in young piglets. Pediatr Res 18:579-583

4. Bradley LM, Czaja JF, Goldstein RE 1990 Circulatory effects of endothelin in newborn piglets. Am J Physiol 259:H1613-H1617

5. Konduri GG, Fewell JE, Taylor BJ, Hill DE 1990 Chlorpromazine attenuates the pulmonary vascular response to isocapneic alveolar hypoxia in piglets. Dev Pharmacol Ther 14:238-244

6. Taylor BJ 1989 Cardiovascular response to histamine during normoxaemia and hypoxaemia in piglets. J Dev Physiol 11:117-121

7. Goldberg RN, Suguihara C, Streitfeld MM, Bancalari A, Clark MR, Bancalari E 1986 Effects of a leukotriene antagonist on the early hemodynamic manifestations of group B streptococcal sepsis in piglets. Pediatr Res 20:1004-1008

8. Troug WE, Sorensen GK, Standaert TA, Redding GJ 1986 Effects of the 
thromboxane synthetase inhibitor, Dazmegrel (UK 38,485), on pulmonary gas exchange and hemodynamics in neonatal sepsis. Pediatr Res 20:481-486

9. Gibson RL, Redding GJ, Henderson WR, Troug W 1991 Group B streptococcus induces tumor necrosis factor in neonatal piglets. Am Rev Respir Dis 143:598-604

10. Gibson RL, Troug WE, Redding GJ 1988 Hypoxic pulmonary vasoconstriction during and after infusion of group B streptococcus in neonatal pigs. Am Rev Respir Dis 137:774-778

11. Troug WE, Gibson RL, Henderson WR, Redding GJ, Standaert TA 1992 Effect of pentoxifylline on cytokine- and eicsanoid-induced acute pulmonary hypertension in piglets. Pediatr Res 31:163-169

12. Gibson RL, Troug WE, Redding GJ 1988 Thromboxane-associated pulmonary hypertension during three types of gram-positive bacteremia in piglets. Pediatr Res 23:553-556

13. Rendas A, Branthwaite M, Lennox S, Reid L 1982 Response of the pulmonary circulation to acute hypoxia in the growing pig. J Appl Physiol 52:811-814

14. Rendas A, Branthwaite M, Reid L 1978 Growth of pulmonary circulation in normal pig: structural analysis and cardiopulmonary function. J Appl Physiol 45:806-817

15. Audi SH, Dawson CA, Rickaby DA, Linehan JH 1991 Localization of the sites of pulmonary vasomotion by use of arterial and venous occlusion. J Appl Physiol 70:2126-2136

16. Dawson CA, Linehan JH, Rickaby DA, Krenz GS 1991 Effect of vasoconstriction on longitudinal distribution of pulmonary vascular pressure and volume. J Appl Physiol 70:1607-1616

17. Nagasaka YJ, Bhattacharya S, Nanjo S, Groppre MA, Staub NC 1984 Micropuncture measurement of lung microvascular pressure profile during hypoxia in cats. Circ Res 54:90-95

18. Shirai M, Sasa K, Ninomiya I 1986 Effects of regional alveolar hypoxia and hypercapnia on small pulmonary vessels in cats. J Appl Physiol 61:440-448

19. Bland RD, Demling RH, Selinger SL, Staub NC 1977 Effects of alveolar hypoxia on lung fluid and protein transport in unanesthetized sheep. Circ Res 40:269-274

20. Koyama T, Horimoto M 1983 Blood flow reduction in local pulmonary microvessels during hypoxia imposed on a small fraction of the lung. Respir Physiol 52:181-189

21. Parker RE, Granger DN, Taylor AE 1981 Estimates of isogravimetric capillary pressures during alveolar hypoxia. Am J Physiol 241:H732-H739

22. Bland RD, Bressack MA, Haberkern CM, Hansen TN 1980 Lung fluid balance in hypoxic, awake newborn lambs and mature sheep. Biol Neonate 38:221228

23. Nelin LD, Krenz GS, Rickaby DA, Linehan JH, Dawson CA 1993 A distensible vessel model applied to hypoxic pulmonary vasoconstriction in the neonatal pig. J Appl Physiol 74:2049-2056

24. Linehan JH, Dawson CA, Rickaby DA, Bronikowski TA 1986 Pulmonary vascular compliance and viscoelasticity. J Appl Physiol 61:1802-1814

25. Audi SH, Dawson CA, Linehan JH 1992 A method for analysis of pulmonary arterial and venous occlusion data. J Appl Physiol 73:1 190-1195

26. Milnor WR 1989 Hemodynamics. William \& Wilkins, Baltimore, pp 58-101

27. Linehan JH, Dawson CA, Rickaby DA 1982 Distribution of vascular resistance and compliance in a dog lung lobe. J Appl Physiol 53:158-168

28. Hakim TS, Kelly S 1989 Occlusion pressure vs. micropipette pressures in the pulmonary circulation. J Appl Physiol 67:1277-1285

29. Gustin P, Urbain B, Delaunois A, Zeimes K, Ansay M 1992 Permeability of the endothelium and partitioning of the pulmonary blood flow resistance in isolated perfused pig lungs: effects of breed and age. Vet Res Commun 16:69-82

30. Brower RG, Wise RA, Hassapoyannes C, Hausknecht M, Permutt S 1986 Longitudinal distribution of vascular compliance in the canine lung. $J$ App Physiol 61:240-247

31. Barman SA, Senteno E, Smith S, Taylor AE 1989 Acetylcholine's effect on vascular resistance and compliance in the pulmonary circulation. $J$ Appl Physiol 67:1495-1503

32. Dawson CA, Forrester TE, Hamilton LH 1975 Effects of hypoxia and histamine infusion on lung blood volume. J Appl Physiol 38:811-816

33. Fike CD, Hansen TN 1987 Hypoxic vasoconstriction increases with postnatal age in lungs from newborn rabbits. Circ Res 60:297-303

34. Mitzner W, Sylvester JT 1981 Hypoxic vasoconstriction and fluid filtration in pig lungs. J Appl Physiol 51:1065-1071

35. Cox RH 1984 Viscoelastic properties of canine pulmonary arteries. Am J Physiol 246:H90-H96

36. Kapanci Y, Assimacopoulos A, Irle C, Zwahler A, Gabbiani G 1974 Contractile interstitial cells in pulmonary alveolar septa: a possible regulator of ventilation/perfusion ratio? J Cell Biol 60:375-392

37. Perrault T, Coe JY, Olley PM, Coceani F 1990 Pulmonary vascular effects of prostaglandin D2 in newborn pig. Am J Physiol 258:H1292-H1299

38. Bowdy BD, Aziz SM, Marple SL, Yoneda K, Pauly TH, Coonrod D, Gillespie MN 1990 Organ-specific disposition of group B streptococci in piglets: evidence for a direct interaction with target cells in the pulmonary circulation. Pediatr Res 27:344-348 